\title{
Erratum to: Design of the INTEGRATE study: effectiveness and cost-effectiveness of a cardiometabolic risk assessment and treatment program integrated in primary
}

\section{care}

\author{
Ilse F Badenbroek ${ }^{1,2^{*}+}$, Daphne M Stol ${ }^{2,1 \dagger}$, Marcus MJ Nielen ${ }^{1}$, Monika Hollander ${ }^{2}$, Roderik A Kraaijenhagen ${ }^{3}$, \\ G Ardine de Wit ${ }^{2,4}$, François $G$ Schellevis ${ }^{1,5}$ and Niek J de Wit ${ }^{2}$
}

\section{Erratum}

\section{Background}

The INTEGRATE study investigates the effectiveness and cost-effectiveness of a "Personalized Prevention Approach for Cardiometabolic risk" (PPA CMR). This is a combination of an online risk estimation as used in the Dutch guideline 'the Prevention consultation' (Dutch PC-guideline) [1] and a tailored lifestyle intervention. The different steps of PPA CMR are described in our protocol [2].

\section{Interim analysis}

First results INTEGRATE

The first interim analysis in October 2014 in 11 practices showed expected response rates of $40 \%$ on the first step. However, the results of the online risk estimation (step 2) were different than expected. Only $27 \%$ of the participants had a score above threshold and was eligible for the third step. This is far less than the $60 \%$ that we had expected, based on results of the pilot study in 2009 [3]. As a consequence, only half of the expected participants proceeds to step 3 of the intervention (additional measurements).

\section{Risk estimation}

The explanation for the difference between the findings is a slight change in the algorithm of the risk score used

\footnotetext{
* Correspondence: I.F.Badenbroek@umcutrecht.nl

${ }^{\dagger}$ Equal contributors

${ }^{1}$ Netherlands Institute for Health Services Research (NIVEL), P.O. Box 1568, Utrecht 3500 BN, The Netherlands

${ }^{2}$ Julius Center, University Medical Center Utrecht, Utrecht, The Netherlands

Full list of author information is available at the end of the article
}

for the 2011 Dutch PC-guideline as compared to the algorithm used in the 2009 pilot study. According to information provided by the guideline team of Dutch College of GPs, responsible for the guideline, the risk score calculation was reassessed before publication in the Dutch PC-guideline.

The assumptions made for the sample size calculation for the INTEGRATE study are based on the results of the risk score calculation in the pilot study.

The guideline authors and the INTEGRATE research team conclude that there is a chance that the risk score calculation as used in the INTEGRATE study could lead to a number of misclassified participants at moderate risk for cardiometabolic diseases (CMD) who score under the threshold. To study this, we have decided to adapt the study protocol.

\section{Amendment in protocol}

In addition to our published protocol we will perform additional measurements in a selection of participants with scores below threshold in April and June 2016. We will invite this group for the same intervention as the participants with a score above threshold.

Criteria for inviting people for additional measurements will be participants with one of the following risk factors for CMD:

- a family history of cardiovascular disease

- BMI $>27$

- smokers aged 50 and older

The results will show the number of newly detected CMD and CMD risk factors in a subgroup of participants 
with scores below threshold. Sensitivity analyses will show in what range the risk estimation is most (cost-) effective. Based on these results we will be able to give advice whether to reassess the threshold of the risk score in the Dutch PC guideline.

\section{Consequences}

- The aim of the study remains unchanged: "the effectiveness and cost-effectiveness of a cardiometabolic risk assessment and treatment program integrated in primary care".

- The sample size calculation is no longer applicable. The intervention group will be smaller than expected in the original protocol. This has consequences for the power of the study. The study might not have sufficient power to detect a difference in the number of smokers. However, the study will have sufficient power to detect differences in the other CMD risk factors such as BMI and blood pressure.

- The cost-effectiveness analysis will be performed according to plan

- Additional measurements will be performed in the last two groups of study participants in April and June 2016 (eligible participants $n=10.000$ ) with risk scores below threshold and aforementioned risk factors for CMD.

\section{Ethics and funding bodies}

The described amendment in our protocol was approved by the UMC Utrecht Institutional Review Board and exempted from full assessment under the Medical Research involving human subjects Act.

We have received additional funding by ZonMw (The Netherlands organization for Health Research and development), Lekker Lang Leven (a collaboration of the Dutch Diabetes Research Foundation, the Dutch Heart Foundation and the Dutch Kidney foundation) and Innovatiefonds Zorgverzekeraars (Healthcare Insurance Innovation Fund) to compensate for the 6 month delay and the costs for the additional measurements. The Dutch College of GPs who developed the Dutch PCguideline fully supports the amendment made in our protocol.

\section{Conclusion}

The amendment in the protocol is in our opinion the best solution to guarantee the validity of the INTEGRATE study. The aim of our study remains unchanged. However, the amendment will enable us to establish the optimal and most cost-effective threshold for the online risk estimation. Furthermore it gives us the opportunity to advice the Dutch College of GP's how to improve the Dutch PC-guideline.

\section{Author details}

${ }^{1}$ Netherlands Institute for Health Services Research (NIVEL), P.O. Box 1568, Utrecht 3500 BN, The Netherlands. ${ }^{2} J u l i u s$ Center, University Medical Center Utrecht, Utrecht, The Netherlands. ${ }^{3}$ NDDO Institute for Prevention and Early Diagnostics (NIPED), Amsterdam, The Netherlands. ${ }^{4}$ Centre for Nutrition, Prevention and Health Care, National Institute of Public Health and the Environment (RIVM), Bilthoven, The Netherlands. ${ }^{5}$ Department of General Practice \& Elderly Care Medicine/EMGO Institute for health and care research, VU University Medical Center, Amsterdam, The Netherlands.

Received: 23 March 2016 Accepted: 23 March 2016

Published online: 06 April 2016

References

1. Dekker J, Alssema M, Janssen P, Van der Paardt M, Festen C, van Oosterhout M, van Dijk J, van der Weijden T, Gansevoort R, Dasselaar J, van Zoest F, Drenthen T, Walma E, Goudswaard A. NHG-standaard Het PreventieConsult module cardiometabool NHG-standaard. Huisarts Wet. 2011:54:138-55.

2. Badenbroek IF, Stol DM, Nielen MM, Hollander M, Kraaijenhagen RA, de Wit GA, Schellevis FG, de Wit NJ. Design of the INTEGRATE study: effectiveness and cost-effectiveness of a cardiometabolic risk assessment and treatment program integrated in primary care. BMC Fam Pract. 2014;15:90.

3. Van der Meer V, Nielen MM, Drenthen AJ, Van Vliet M, Assendelft WJ, Schellevis FG. Cardiometabolic prevention consultation in the Netherlands: screening uptake and detection of cardiometabolic risk factors and diseases - a pilot study. BMC Fam Pract. 2013;14:29.

Submit your next manuscript to BioMed Central and we will help you at every step:

- We accept pre-submission inquiries

- Our selector tool helps you to find the most relevant journal

- We provide round the clock customer support

- Convenient online submission

- Thorough peer review

- Inclusion in PubMed and all major indexing services

- Maximum visibility for your research 